\title{
Learning from Alma Ata: The Medical Home and Comprehensive Primary Health Care
}

\author{
Laura M. Gottlieb, MD, MPH
}

The patient-centered medical home (PCMH) recently has received much attention in health systems literature. The PCMH holds considerable promise for improving health outcomes and re-establishing a role for family medicine in a fragmented health care system. Despite its philosophical approach to comprehensive health care reform, the PCMH fails to offer concrete recommendations to address the social determinants of health, which include health and social policy. Political engagement to promote health is part of both primary health care and specifically family medicine's history; the absence of practical, adaptable ways to implement this engagement may undermine the PCMH's ultimate goals of improving individual and population health. (J Am Board Fam Med 2009;22:242-6.)

"The drumbeat for the patient-centered medical home is getting louder," wrote Bowman, Neale, and Lupo ${ }^{1}$ in their introduction to a recent fournal of the American Board of Family Medicine. Hailed as a "polestar" in that same issue, ${ }^{2}$ the medical home's appearance and rapid spread in both recent primary care literature and financing legislation ${ }^{3}$ come at an important time in US history. Increasing health disparities and poor outcomes continue to defy America's high per capita health spending ${ }^{4,5}$; the recent political elections highlight the population's interest in concrete reform. With strong evidence supporting its platform, the medical home movement is poised to be at the helm during this new tide. It may decrease provider shortages, ${ }^{6}$ adverse medical events, ${ }^{7}$ and hospitalizations ${ }^{8}$; it is likely to improve high quality care, ${ }^{7,9}$ cost-effectiveness, ${ }^{10}$ and patient satisfaction levels. ${ }^{11,12}$ However, while we move forward, John Rogers ${ }^{13}$ caution echoes loudly: the patient-centered medical home $(\mathrm{PCMH})$ cannot be considered a panacea cure for what ails

This article was externally peer reviewed.

Submitted 12 September 2008; revised 14 December 2008; accepted 22 December 2008.

From First Choice Community Healthcare, Department of Family and Community Medicine, University of New Mexico, Albuquerque.

Funding: The author is partially supported through $\mathrm{Na}-$ tional Institute of Mental Health grant R25MH060288-09.

Conflict of interest: none declared.

Corresponding author: Laura M. Gottlieb, MD, MPH, Department of Family and Community Medicine, University of New Mexico, 1231 Candelaria Road NW, Albuquerque, New Mexico 87107 (E-mail: lgottlieb@salud.unm.edu). primary health care. Nonetheless, its proposal gives primary care-and family medicine more specifically-a unique opportunity to review the premise and promise of our specialty.

As doctors for a low-income, largely uninsured clinic population, my colleagues and I are bombarded daily by the social determinants of health. Our patients lack access to employment and safe housing, suffer violence and discrimination in their communities, and experience hopelessness and low levels of civic engagement. The evidence continues to mount that these social factors have wide-ranging health effects. ${ }^{14-19}$ The current recession, the worst in more than 30 years, is likely to exacerbate many of these causes of illness, widening disparities in health outcomes on economic, racial, and ethnic scales $^{20}$ and in clinic networks beyond those that target under-served populations. As we carefully examine the benefits of any new proposal, the question must arise: Will the envisioned model improve the social situations that lead to poor health? And moreover, should it?

Since the conception of public health, there has been controversy surrounding the clinical versus the social domain of medicine. Sir Michael Marmot, Chair of the World Health Organization's Commission on Social Determinants of Health and Director of the International Institute for Society and Health, describes the dilemma succinctly: "A physician faced with a suffering patient has an obligation to make things better. If she sees $100 \mathrm{pa}-$ tients the obligation extends to all of them. And if 
a society is making people sick?" ${ }^{21}$ What then? Where does the realm of clinical medicine stop and the realm of public health begin? Though the social gradients of illness and mortality gained fame with the Whitehall studies on British civil servants ${ }^{22,23}$ they are now part of international studies on multiple morbidities, including cardiovascular disease, ${ }^{24}$ depression, ${ }^{25}$ tobacco use, ${ }^{26}$ and obesity. ${ }^{18}$ With this growing body of literature, the distinction between clinical and non-clinical is more blurred than ever.

This disorientation between clinical and nonclinical domains is an important part of primary care's history. The 1978 International Conference on Primary Care held at Alma Ata is regarded as a landmark event for promoting and distributing the concept of primary health care over primary medical care. ${ }^{27}$ In contrast to isolated clinical practice, primary health care was expected to focus on health and prevention, health promotion, continuous and comprehensive care, team approaches, intersectoral collaboration, and community participation. This was to be done through a combination of practical, strategic, and philosophic reforms. At Alma Ata, the World Health Organization's director general Halfdan T. Mahler reflected the enthusiasm for this comprehensive reform when he asked the 3000 delegates from 134 nations in attendance, "Are you ready to introduce, if necessary, radical changes in the existing health delivery system so that it properly supports primary health care as the overriding health priority? Are you ready to fight the political and technical battles required to overcome any social and economic obstacles and professional resistance to the universal introduction of primary health care?"28 Ultimately, the Alma Ata attendees divided along 2 schools of thought that viewed primary health care discrepantly. There were those that believed in Mahler's version of comprehensive primary health care, which defined health care as a human right, one that if necessary incorporated the "re-shaping of global developmental designs to include community participation." 29 In contrast, others emphasized selective primary care, which focused more directly on health care delivery systems. The differences between selective and comprehensive primary health care arguably is repackaged today in the distinction between the clinical and non-clinical domains, or even medicine and public health.
The Alma Ata Declaration anticipated "health for all" by the year 2000. In their report "Primary health care as a strategy for achieving equitable care," De Maeseneer and colleagues ${ }^{29}$ summarize hypotheses regarding why Alma Ata's goals were not achieved. Some of those failures are attributed to the philosophical conflicts between selective and comprehensive primary health care; the failure to engage clinicians; and the presence of ideology over concrete, adaptable practice recommendations. In their review ${ }^{29}$ commissioned by the Health Systems Knowledge Network for the World Health Organization, De Maeseneer's group goes on to recommend a central role for primary health care in achieving international health equity, one that incorporates multidisciplinary community-oriented primary health care teams and addresses the social determinants of health. More simply stated, their recommendations suggest primary health care encompass political and social reform.

Despite Marmot's warning that "some doctors feel queasy at the prospect of social action to improve health," ${ }^{21}$ family medicine's first leaders were from the Alma Ata generation. Pisacano, Zervanos, and others were the revolutionaries that Taylor describes in his 2006 essay on the "The Promise of Family Medicine." 30 "The initial promise of family medicine," Taylor writes, "was that we would rescue a fragmented health care system, put it together again and return it to the people." ${ }^{30}$ In that vein, the authors of the American Academy of Family Physicians (AAFP)-affiliated Robert Graham Center's 2007 report on the PCMH cite the goals of Alma Ata, and incorporate Alma Ata's language in the PCMH mission: "Primary care involves, in addition to the health sector, all related sectors and aspects of national and community development, in particular... food, industry, education, housing, public works, communication and other sectors; and demands the coordinated efforts of all those sectors." 31

Now endorsed by the American College of Physicians, the American Osteopathic Association, the American Academy of Pediatrics and the AAFP, the $\mathrm{PCMH}$ has been distilled into 7 core principles, including a "whole person orientation" and "coordinated care." In the Graham Center report, a more detailed discussion of the "whole person orientation" articulates that the PCMH look at the community, especially when addressing the social determinants of health. "This means that the 
PCMH will need to have capacity for the integration of primary health care with public health approaches. Primary care is best poised for this role but there is little support for this function. Community, the social environment we live in and its capacity for both harm and good are integral to personal health." The words are reminiscent of Alma Ata's vision, and even Virchow's historical pronouncement, "If medicine is to fulfill her great task, then she must enter the political and social life." 32

And so, balanced at a critical moment in history, armed with a vision of widespread reform, the $\mathrm{PCMH}$ moves from rhetoric to concrete recommendations. At this point, however, irresolution belies the philosophically comprehensive appeal. The same weaknesses that led Alma Ata to fail to meet its goals emerge in the academic summary. Rather than offering tools for implementing this vision of comprehensive primary health care, the limited recommendations resonate more with selective primary health care, confined in scope and substance. To help family physicians act as the "natural attorneys of the disadvantaged," the Graham Center report suggests community agency linkages to help indigent patients obtain social services; it does not address the roles that political and social environments play universally in health care access and outcomes. The PCMH recommends developing partnerships with local health departments to share data and to plan interventions; it does not identify steps to help providers engage in local or national struggles to create employment opportunities, ensure health benefits, raise minimum wages, end racial discrimination, or improve recreation opportunities. Though the medical home theoretically includes a 'team approach' that will include social workers, behaviorists, health educators, specialists, pharmacists, and physical and occupational therapists, surprisingly absent is a call for political or social involvement. Not mentioned are the community activists and advocates that may foment the requisite policy change to improve many of our socially determined health outcomes.

Here lies an opportunity thus far missed, a chance to play a different hand from the one lost at Alma Ata, whose critics identified precisely these errors that we seem destined to repeat: a conflict between selective and comprehensive primary health care, an inability to engage primary health care providers, a chasm between short-term changes and the need for comprehensive reform. The PCMH could respond to these challenges. Why not give concrete recommendations for social engagement with options for adaptation, recruit and empower the provider community, and develop both short- and long-term models? Is it a fear that the steps that lead to comprehensive primary health care are too radical? In today's political climate, delicately balanced between left and right, incrementalism - the slow march toward reformis assured; accepting this challenge does not necessitate more dramatic overhaul. Instead, the absence of recommendations to create political and social reform in the initial proposals of the PCMH seems more likely because of the lack of a prototype from which to model that reform.

Family medicine is well suited to meet this challenge of engagement, to develop a language and a method for securing the border between clinical and non-clinical frontiers. This was the initial promise of family medicine and it is the premise on which the specialty now sits, perched at the intersection of individual, family, and community. Family medicine could create the prototype for social and political engagement, test and evaluate it, and then report to a national audience. We could add a practical dimension to what has been philosophically proposed. Family medicine could detail a range of activities and/or requirements that define its commitment to political and social responsibility. These could be limited in scope to begin: encourage widespread continuing education in community health advocacy and create a community development wing at the AAFP with specific research aims and grant funding. These activities could be more involved as the PCMH model develops and as more science demonstrates the power of policy transformation: increase medical school and residency requirements in advocacy and policymaking; make board certification contingent on policy continuing medical education; compel community health centers to have local legislative representatives on advisory boards; and integrate community advocates/health workers into practice models and funding opportunities. Certainly physicians alone cannot take on the task of bridging the clinical and non-clinical, changing policy and social circumstance while at the same time learning disease and development patterns, formularies, and service guidelines. But can we confine ourselves to what has been traditionally "clinical" with growing 
evidence that the distinction between clinical and non-clinical is ill conceived?

When it announces a commitment to reconstruct primary health care, the PCMH bursts with potential. Its mission and core principles promote comprehensive reform at an incrementalist pace, one that the public policy process is likely to embrace. But it is critical that the action items to reach that reform, no matter how small their initial scope, reflect the comprehensive vision from which they are derived and include providers of primary care in their midst. That vision portrays primary health care as both inside and outside the clinical domain. So if we do indeed embrace comprehensive primary health care, we must address the failures of Alma Ata to outline a successful plan for implementation. As medicine grows to fulfill "her great task," she should at least be armed with lessons from history.

The author thanks Brian M. Johnson, MD, for his comments on the manuscript.

\section{References}

1. Bowman MA, Neale AV, Lupo P. The medical home. Health services and clinical family medicine research. J Am Board Fam Med 2008;21:367-9.

2. Daaleman J. The medical home: locus of physician formation. J Am Board Fam Med 2008;21:451-7.

3. Barr M. The need to test the patient-centered medical home. JAMA 2008;300:834.

4. National Coalition on Health Care. Health care quality: facts on the quality of health care. Available from http://www.nchc.org/facts/quality.shtml. Accessed 11 December 2008.

5. National Coalition on Health Care. Health insurance costs: facts on the cost of health insurance and health care. Available from http://www.nchc.org/ facts/cost.shtml. Accessed 11 December 2008.

6. Grumbach K, Bodenheimer T. A primary care home for Americans: putting the house in order. JAMA 2002;288:889-93.

7. Starfield B. Primary care [video presentation]. Available from http://www.pcpcc.net/content/primary-carevideo-presentation-dr-barbara-starfield. Accessed 9 September 2008.

8. Starfield B. Primary care: balancing health needs, services, and technology. New York: Oxford University Press; 1998.

9. Franks P, Fiscella K. Primary care physicians and specialists as personal physicians: health care expenditures and mortality experience. J Fam Pract 1998; 47:105-10.

10. Greenfield S, Nelson EC, Zubkoff M, et al. Variations in resource utilization among medical special- ties and systems of care: results from the Medical Outcomes Study. JAMA 1992;267:1624-30.

11. Stewart AL, Grumback K, Osmond DH, Vranizan K, Komoraomy M, Bindman AB. Primary care and patient perceptions of access to care. J Fam Pract 1997;44:177-85.

12. Griffin SJ, Kinmonth AL, Veltman MW, Gillard S, Grant J, Stewart M. Effect of health-related outcomes of interventions to alter the interaction between patients and practitioners: a systematic review of trials. Ann Fam Med 2004;2:595-608.

13. Rogers JC. The patient-centered medical home movement-promise and peril for family medicine. J Am Board Fam Med 2008;21:370-4.

14. Muntaner C. Teaching social inequalities in health: barriers and opportunities. Scand J Public Health 1999;27:161-5.

15. Krieger N. Epidemiology and the web of causation. Has anyone seen the spider? Soc Sci Med 1994;39: 887-903.

16. Wilson WJ. The truly disadvantaged: the inner city, the underclass and urban policy. Chicago (IL): University of Chicago Press; 1987.

17. Lutsey PL, Diez Roux AV, Jacobs DR Jr, et al. Associations of acculturation and socioeconomic status with subclinical cardiovascular disease in the multi-ethnic study of atherosclerosis. Am J Public Health 2008;98:1963-70.

18. Kim D, Subramanian SV, Gortmaker SL, Kawachi I. US state- and county-level social capital in relation to obesity and physical inactivity: a multilevel, multivariable analysis. Soc Sci Med 2006;63:1045-59. Epub 2006 Apr 27.

19. Krieger N. Defining and investigating social disparities in cancer: critical issues. Cancer Causes Control 2005;16:5-14.

20. Daugherty JC. Effects of the 1974-75 recession on health care for the disadvantaged. National Center for Health Services Research Report DHEW-PHS79-3248; 1980:1-94.

21. Marmot M. Health in an unequal world. Lancet 2006;368:2081-94.

22. Marmot MG, Rose G, Shipley M, Hamilton PJS. Employment grade and coronary heart disease in British civil servants. J Epidemiol Community Health 1978;32:244-9.

23. Marmot M, Stansfeld S, Patel C, et al. Health inequalities among British civil servants: the Whitehall II study. Lancet 1991;337:1387-93.

24. Squares BP. Cardiovascular disease and socioeconomic status. CMAJ 2000;162:S3.

25. Hudson CG. Socioeconomic status and mental illness: tests of the social causation and selection hypotheses. Am J Orthopsychiatry 2005;75:3-18.

26. Bolte G, Fromme H, GME Study Group. Socioeconomic determinants of children's environmental tobacco smoke exposure and family's home smoking policy. Eur J Public Health 2009;19:52-8. 
27. Vuori H. Health for all, primary health care and general practitioners. J R Coll Gen Pract 1986;36: $398-402$.

28. Intervention of Director General of WHO, $\mathrm{H}$. Mahler. In: Statements by Participants in the Plenary Meetings, Alma Ata, International Conference on Primary Health Care, 6-12 September 1978. Geneva: World Health Organization. As cited in Cueto M. The origins of primary health care and selective primary health care. Am J Public Health 2004;94:1864-74.

29. De Maeseneer J, Willems S, De Sutter A, Van de Geuchte ML, Billings M. Primary health care as a strategy for achieving equitable care: a literature review commissioned by the Health Systems Knowledge Network. Available from http://www.who.int/ social_determinants/resources/csdh_media/primary_ health_care_2007_en.pdf. Accessed 21 November 2008.

30. Taylor RB. The promise of family medicine: history, leadership and the Age of Aquarius. J Am Board Fam Med 2006;19:183-90.

31. Robert Graham Center. The patient-centered medical home: history, seven core features, evidence and transformational change. Monograph. Center for Policy Studies in Family Medicine and Primary Care (2007). Available from http://www.graham-center. org/online / etc/medialib/graham / documents / publications/mongraphs-books/2007/rgcmo-medicalhome.Par.0001.File.tmp/rgcmo-medical-home.pdf. Accessed 10 December 2008.

32. Friedlander E. Rudolf Virchow on pathology education. Available from http://www.pathguy.com/ virchow.htm. Accessed 10 December 2008. 